\title{
A comparative study on applicability of nano-sized iron(II, III) oxide in ultrasonicated Fenton process
}

\author{
Serkan Sahınkaya ${ }^{\dagger}$, Sennur Merve Yakut \\ Department of Environmental Engineering, Nevsehir Haci Bektas Veli University, Nevsehir, Turkey
}

\begin{abstract}
Fenton process is one of the most effective advanced oxidation processes for the removal of pollutants from wastewater. In this study, while ferrous iron was used in conventional Fenton process (CFP); nano-sized iron(II, III) oxide was experienced in modified Fenton process (MFP) as a new catalyst alternative. In order to enhance their oxidation efficiencies, both CFP and MFP were combined with ultrasonication at 53 $\mathrm{kHz}$ fixed frequency. Thus, the influences of both catalyst iron species and ultrasonication on color and chemical oxygen demand (COD) removals from synthetic textile wastewater including Maxilon Red GRL 200\% dyestuff were investigated experimentally. While the COD and color removal rates were found as $72.5 \%$ and $69.7 \%$ via CFP; they were $87 \%$ and $75.8 \%$ by ultrasonicated CFP, respectively. The color and COD removals were $40.6 \%$ and $64.8 \%$ via MFP, and 49.9 and $73.1 \%$ by ultrasonicated MFP, respectively. Therefore, it was found that the simultaneously usage of ultrasonication with CFP and MFP was improved the COD and color removal efficiencies and oxidation rates even at lower $\mathrm{H}_{2} \mathrm{O}_{2}$ dosages, compared to individual CFP and MFP. Moreover, the color and COD removal kinetics were also modelled mathematically and compared in the study.
\end{abstract}

Keywords: COD, Color removal, Fenton, Textile wastewater, Ultrasonication

\section{Introduction}

Textile industry is one of the most important industrial branches in developing countries. However, most of the dyes in textile wastewaters are biologically non-degradable and toxic for the aquatic and soil life. These kind of wastewaters containing high-concentrated organic materials and dyestuff decrease oxygenetation capacity of aquatic system and give rise to the death of aquatic species. In fact, the presence of a very small amount of dye in water (less than $1 \mathrm{mg} / \mathrm{L}$ for some dyes) is highly visible and enough to present an aesthetic problem [1, 2]. For these reasons, discharging of such wastwaters into receiving aquatic ecosystems without suitable and adequate treatment results in irreversible environmental damages.

There are many chemical methods for the treatment of textile wastewaters. One of them is Fenton process, which is an advanced oxidation process (AOP). This process is based on the production of hyroxyl radicals $(\mathrm{OH})$ as a result of the reaction between ferrous iron $\left(\mathrm{Fe}^{2+}\right)$ and hydrogen peroxide $\left(\mathrm{H}_{2} \mathrm{O}_{2}\right)$ under strong acidic con-

This is an Open Access article distributed under the term of the Creative Commons Attribution Non-Commercial License (http://creativecommons.org/licenses/by-nc/3.0/) which permits unrestricted non-commercial use, distribution, and reproduction in any medium, provided the original work is properly cited.

Copyright (C) 2020 Korean Society of Environmental Engineers ditions [3, 4]. The basic reaction equations of Fenton process are presented in Eq. (1) and (2) [5]. The reaction rate and oxidation efficiency of the process is based on the concentrations of catalyst iron and hydrogen peroxide in the reaction medium. As the amounts of reactants in the medium decrease, the production of oxidant hyroxyl radicals $\left(\mathrm{OH}^{\circ}\right)$ also slows down and therefore, the reaction rate and efficiency is also reduced [5]. On the other hand, excess presence of Fenton reactants results in the radical scavenging effect, which reduce the removal efficiency and rate of target pollutants in the solution [3].

$$
\begin{gathered}
\mathrm{Fe}^{2+}+\mathrm{H}_{2} \mathrm{O}_{2} \rightarrow \mathrm{Fe}^{3+}+\mathrm{OH} \cdot+\mathrm{OH}^{-} \\
\mathrm{RH}+\mathrm{OH} \cdot \rightarrow \mathrm{H}_{2} \mathrm{O}+R^{\cdot}
\end{gathered}
$$

In coventional Fenton process (CFP), ferrous iron $\left(\mathrm{Fe}^{2+}\right)$ is utilized as a catalyst. The process can be modified by changing the species of catalyst iron. Such processes are generally called as "modified Fenton process (MFP)". Within the scope of this study, nano-sized iron(II, III) oxide $(<50 \mathrm{~nm})$ is used as an alternative

Received August 7, 2018 Accepted January 29, 2019

${ }^{\dagger}$ Corresponding author

Email: serkansahinkaya@gmail.com

Tel: +90-384-228-1000

ORCID: 0000-0002-0176-4198 
source of catalyst iron. When nano-sized iron(II, III) oxide is added to the reaction system, the oxidation process is performed according to the reactions in Eq. (1) and (3) because of its ferrous oxide and ferric oxide content [3], after dissolution of solid catalyst iron. The continuation of the reaction is performed as in CFP.

$$
\mathrm{Fe}^{3+}+\mathrm{H}_{2} \mathrm{O}_{2} \rightarrow \mathrm{Fe}^{2+}+\mathrm{HOO} \cdot+\mathrm{H}^{+}
$$

Ultrasonication has recently attracted the attention of researchers for the removal of pollutants from wastewaters. In this process, when ultrasound at high frequency is applied to the liquid medium, micro-sized bubbles are formed, developed and collapse in microseconds. The collapse of micro-bubbles creates "hot spots" with extreme conditions at $5,000^{\circ} \mathrm{C}$ temperature and 500 atm pressure [6, 7]. These extreme conditions cause mainly two pollutant removal mechanisms in the aqueous medium: (1) production of strong free oxidizing agents (Eq. (4)) such as $\mathrm{OH}^{*}, \mathrm{O}^{*}, \mathrm{~N}^{*}, \mathrm{H}^{*}$ and $\mathrm{H}_{2} \mathrm{O}_{2}$, and (2) pyrolysis of volatile hydrophobic pollutants in the bubbles at high temperature and pressure [6]. While the hydrophilic materials such as the dyes and sizing chemicals present in the textile wastewaters are oxidized by free radicals in the solution; hydrophobic chemicals like phenol compounds are degraded mostly within the hot spots. Ultrasonication is an eco-friendly oxidation process using in a wide $\mathrm{pH}$ range without chemical addition and it can be combined with other advanced oxidation processes in order to improve the oxidation capacity. That is, the oxidation rate and efficiency can be augmented with increasing amount of the free radicals produced by the simultaneous oxidation mechanisms of the combined processes. Moreover, the regeneration of iron oxide compounds such as $\mathrm{Fe}-\mathrm{O}_{2} \mathrm{H}^{+2}$ (which is a reaction product of Fenton process and reacts with $\mathrm{H}_{2} \mathrm{O}_{2}$ more slowly than $\mathrm{Fe}^{2+}$ in the process) is also possible by ultrasonication in the combined process (Eq. (5)) [8].

$$
\begin{gathered}
\left.\left.\left.\mathrm{H}_{2} \mathrm{O}\right)\right)\right) \mathrm{OH} \cdot+\mathrm{H} \cdot \\
\left.\left.\left.\mathrm{Fe}-\mathrm{O}_{2} \mathrm{H}^{2+}\right)\right)\right) \mathrm{Fe}^{2+}+\mathrm{HO}_{2} .
\end{gathered}
$$

In the literature, there are many studies on chemical oxygen demand (COD) and color removals from the wastewaters by individual Fenton and ultrasonication processes. However, there are a limited number of studies related to the usage of simultaneously combination of CFP and ultrasonication processes for the treatment of textile wastewaters. A study by Cetinkaya et al. [9] compared CFP with ultrasonicated CFP (U-CFP) based on the removals of COD and color. The result of their study indicated that the combination of ultrasonication with CFP enhanced both
COD and color removal efficiencies even at lower concentrations of Fenton reagents and the U-CFP can be used for the decolorization of textile wastewater to save reaction time and chemical costs. In another study by Sahinkaya [8] performed with cast iron anode and cathode, the oxidation rate and efficiency of ultrasonicated electro-Fenton process were higher because of the extra generation of oxidizing agents in ultrasonicated electro-Fenton process, compared to electro-Fenton process. On the other hand, we could not meet any comparative studies on either MFP (which is utilizing nano-sized Fe(II, III) oxide as the catalyst iron source) or the combination of MFP with ultrasonication (U-MFP) for the removals of COD and color from the synthetic textile wastewater. In the present study, it was aimed to investigate the synergistic effects influencing the COD and color removals from the synthetic textile wastewater by U-CFP and U-MFP. For this aim, the effects of initial pH, species and amount of catalyst iron (ferrous iron and nano sized iron(II, III) oxide) and amount of hydrogen peroxide were investigated with and without ultrasonication. Moreover, kinetics analyses of these four processes were performed for the COD and color removals.

\section{Materials and Methods}

\subsection{Materials}

The chemicals used in the study were all analytical grade purchased from Merck and Aldrich (Germany). The synthetic textile wastewater was prepared using Maxilon Red GRL 200\% (MR GRL) dyestuff, which was obtained commercially from a textile factory, since this dyestuff is one of the most utilized azo dyes by textile industry in Turkey. The chemical structure of the dye is illustrated in Fig. 1. The synthetic textile wastewater was prepared by using ultra pure water according to the study of Sahinkaya [8] and its chemical composition is presented in Table 1.

Table 1. Chemical Content of Synthetic Textile Wastewater [5]

\begin{tabular}{lcc}
\hline Chemical materials & Amount $(\mathbf{m g} / \mathbf{L})$ & Function \\
\hline MR GRL & 200 & Coloring agent \\
Starch & 2,500 & Sizing agent \\
$\mathrm{Na}_{2} \mathrm{CO}_{3}$ & 1,000 & Fixing agent \\
$\mathrm{NaHCO}_{3}$ & 1,000 & Fixing agent \\
$\mathrm{NaCl}$ & 1,500 & Fixing agent \\
$\mathrm{NaOH}$ & 500 & Hydrolysis \\
$\mathrm{H}_{2} \mathrm{SO}_{4}$ & 300 & pH neutralization \\
\hline
\end{tabular}<smiles>CN(Cc1ccccc1)c1ccc(N=NC2N(C)C=NN2C)cc1</smiles>

Fig. 1. Chemical structure of Maxilon Red GRL 200\% dyestuff. 
The maximum wavelength of MR GRL dye was measued as $529 \mathrm{~nm}$ by using UV-visable spectrophotometer (Thermo Scientific, USA). $\mathrm{pH}$ measurements were performed by using a $\mathrm{pH}$ meter (Hach Lange, Germany).

\subsection{Experimental Study}

The CFP and MFP experiments were performed by using 500 $\mathrm{mL}$ synthetic textile wastewater in a jar tester at room temperature. In these experiments, the influences of initial $\mathrm{pH}$ (1-10) and dosages of catalyst iron and hydrogen peroxide (25-600 mg/L) were researched separately in each process. Firstly, the initial pH of synthetic wastewater was adjusted to the desired value, and later on, catalyst iron and hydrogen peroxide were added into the reaction solution, respectively. Then, it was assumed that 1-h reaction period was started by the addition of Fenton reactants. During the reaction step of Fenton process, the reaction mixture was stirred at $90 \mathrm{rpm}$. At the end of this period, the mixing rate was slowed down to $30 \mathrm{rpm}$ and, the final $\mathrm{pH}$ was adjusted to about 7.5 by using 0.1 and $6 \mathrm{~N} \mathrm{NaOH}$ solutions. After the 30-min settling period, the sample was pipeted from supernatant for the analyses.

The U-CFP and U-MFP experiments were also carried out at room temperature as mentioned procedure above. However, these experiments were performed in an ultrasonic water bath, working at a frequency of $53 \mathrm{kHz}$ and a power of $50 \mathrm{~W}$, equipped with a mechanical stirrer. Besides, in order to observe the individual oxidation effect of ultrasonication on the color and COD removals, an experiment was implemented under the same conditions in the absence of Fenton reagents.

At the end of these experiments, the samples were added into the beakers containing $\mathrm{MnO}_{2}$ for degrading the unreacted (residual) $\mathrm{H}_{2} \mathrm{O}_{2}$ to prevent its positive influence on COD [5]. Later on, all samples were filtered through $0.45 \mu \mathrm{m}$ membran filter in order to remove $\mathrm{MnO}_{2}$ and $\mathrm{Fe}(\mathrm{OH})_{3}$ flocs. The color measurements were directly performed by using an UV-vis spectrophotometer at the maximum wavelength of MR GRL dye (529 nm). COD measurements, on the other hand, were carried out according to the Standard Methods [10].

\section{Results}

\subsection{Effect of $\mathrm{pH}$}

The initial $\mathrm{pH}$ of the reaction solution is one of the most important parameters that determines the oxidation efficiency of Fenton process. The solution $\mathrm{pH}$ controls both solubility and species of the catalyst iron $\left(\mathrm{Fe}^{2+} / \mathrm{Fe}^{3+}\right)$. Moreover, the stability of hydrogen peroxide and amount of the hydroxyl radicals $\left(\mathrm{OH}^{*}\right)$ produced in the reaction solution are depended on the solution $\mathrm{pH}$. For these reasons, the effects of initial $\mathrm{pH}$ were examined in the $\mathrm{pH}$ range of 1-10 in the first stage. While $\mathrm{Fe}^{+2}$ and $\mathrm{H}_{2} \mathrm{O}_{2}$ concentrations were kept constant at $300 \mathrm{mg} / \mathrm{L}$ in the CFP and U-CFP experiments; iron(II, III) oxide and $\mathrm{H}_{2} \mathrm{O}_{2}$ concentrations were $100 \mathrm{mg} / \mathrm{L}$ and $300 \mathrm{mg} / \mathrm{L}$ in the MFP and U-MFP experiments, respectively.

The effects of initial $\mathrm{pH}$ on the color and COD removals from the wastewater are illustrated in Fig. 2. As presented in these graph, CFP was more effective than MFP. The maximum color and COD removal efficiencies by CFP were obtained at $\mathrm{pH} 4$ as 95\% and $80.9 \%$, respectively. Because the catalyst iron utilized in CFP was the dissolved form (ferrous ion $\left(\mathrm{Fe}^{2+}\right)$ ) ready to react, compared with MFP. Thus, Fenton reaction (Eq. (1)) was occured more quickly, and produced much more oxidizing hydroxyl radicals. Moreover, as a nature of Fenton reaction, the solution $\mathrm{pH}$ slightly decreased during the reaction period. In CFP, the initial $\mathrm{pH}$ (that was adjusted to 4) droped to about 3 in a few minutes, after the additions of Fenton reagents. The reasons for the drop in $\mathrm{pH}$ in CFP are the acidic characteristics of ferrous sulphate heptahydrate using as ferrous iron source, $\mathrm{H}^{+}$production in the Fenton reaction and insufficiency of buffering capacity of the wastewater. In MFP, there was no significant decrease in the solution $\mathrm{pH}$ because of the dosing of iron(II, III) oxide in the undissolved (solid) form to the reaction mixture. At pH 3, 65.9\% COD and $39.3 \%$ color removals were achieved by MFP. Hereby, the optimized $\mathrm{pH}$ value was decided as 3 for MFP.

The color and COD removals were significantly increased in U-CFP and U-MFP, as a result of applying together with ultrasonication. At $\mathrm{pH} 4$, which was found as the optimum value for U-CFP, the color and COD removals were found as $98.3 \%$ and $91.9 \%$; whereas for U-MFP, they were found as $39.9 \%$ and $71.4 \%$ at $\mathrm{pH} 4$, respectively. The reasons of the increases in the oxidation efficiencies are due to additional production of hydroxyl radicals and transformation of $\mathrm{Fe}^{+3}$ into $\mathrm{Fe}^{+2}$ by ultrasonication (Eq. (4) and (5)) [8].

Strong acidic conditions are required in order to perform Fenton reaction. However, as seen from Fig. 2, the color and COD removal efficiencies obtained at $\mathrm{pH} 1$ and 2 by CFP, U-CFP, MFP and
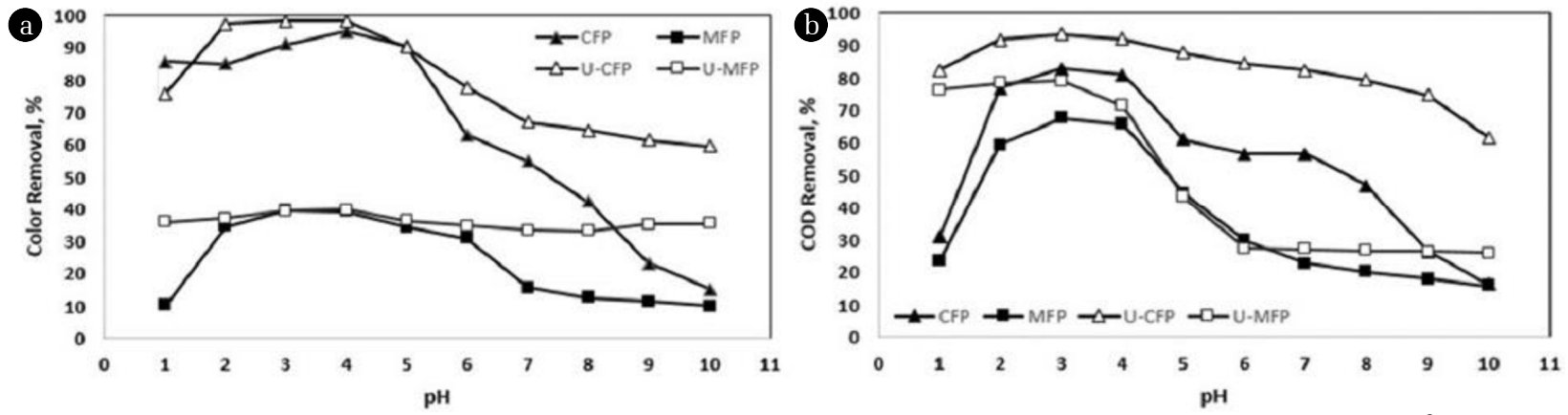

Fig. 2. Effects of the initial $\mathrm{pH}$ on $\mathrm{COD}$ and color removals from the synthetic textile wastewater. [Experimental conditions: $\left[\mathrm{Fe}^{2+}\right]=300 \mathrm{mg} / \mathrm{L}$, $\left[\mathrm{H}_{2} \mathrm{O}_{2}\right]=300 \mathrm{mg} / \mathrm{L}$ in CFP and U-CFP; [Fe(II, III) oxide] $=100 \mathrm{mg} / \mathrm{L},\left[\mathrm{H}_{2} \mathrm{O}_{2}\right]=300 \mathrm{mg} / \mathrm{L}$ in MFP and U-MFP]. 
U-MFP processes were lower than those obtained at $\mathrm{pH} 3$ and 4. The reasons of these results might be (1) scavenging effect of excess hydrogen ion $\left(\mathrm{H}^{+}\right)$on free hydroxyl radicals at strongly acidic conditions $(<3$ ) (Eq. (6)), (2) transformation of hydrogen peroxide to much more stable hydroperoxonium ion $\left(\mathrm{H}_{3} \mathrm{O}_{2}{ }^{+}\right)$(Eq. (7)), and (3) formation of iron(II) hydroxide $\left(\mathrm{Fe}(\mathrm{OH})^{2+}\right)$, which slowly reacts with hydrogen peroxide [3]. Besides, in MFP and U-MFP, the Fenton reaction starts slowly, since the solid nano-sized iron(II, III) oxide should be dissolved first in the reaction mixture as $\mathrm{Fe}^{2+}$ and $\mathrm{Fe}^{3+}$ ions. Later on, the reactions (occurring after the dissolution of solid catalyst iron in the MFP and U-MFP) are performed according to Eq. (1) and (3). Therefore, COD and color removal efficiencies in both MFP and U-MFP were obtained quite lower than CFP and U-CFP.

$$
\begin{gathered}
\mathrm{H}_{2} \mathrm{O}_{2}+\mathrm{H}^{+} \rightarrow \mathrm{H}_{3} \mathrm{O}_{2}^{+} \\
\mathrm{OH} \cdot+\mathrm{H}^{+}+e^{-} \rightarrow \mathrm{H}_{2} \mathrm{O} \\
\mathrm{OH} \cdot+\mathrm{Fe}^{+2} \rightarrow \mathrm{OH}^{-}+\mathrm{Fe}^{+3}
\end{gathered}
$$

\subsection{Effect of Iron Concentration}

Since amount and species of catalyst iron affect both the efficiency and cost of Fenton process [11], it is another important parameter to be optimized. Because, if there is excess amount of iron in the reaction solution, hydroxyl radicals react with $\mathrm{Fe}^{2+}$ ions and it causes the radical scavenging effect (Eq. (9)) [3, 12]. Thus, oxidation capacity as well as pollutant removal efficiency decrease. Moreover, increase in iron dosage results in an increase in the amount of chemical sludge, which might be toxic character [13]. The management of this sludge also increases the operating cost of the process.

$$
\mathrm{Fe}^{2+}+\mathrm{HO} \cdot \rightarrow \mathrm{Fe}^{3+}+\mathrm{OH}
$$

In this study, the $\mathrm{H}_{2} \mathrm{O}_{2}$ concentration was kept constant at 300 $\mathrm{mg} / \mathrm{L}$ in order to optimize catalyst iron dosages in the processes. As the catalyst iron source, ferrous sulphate heptahydrate was used in CFP and U-CFP processes, whereas nano-sized $(<50 \mathrm{~nm})$ iron(II, III) oxide was utilized in MFP and U-MFP processes. The optimization of catalyst iron concentration for U-CFP process was investigated in the range of $10-300 \mathrm{mg} / \mathrm{L}$, whereas the range was 50-600 for CFP, and 25-400 mg/L for MFP and U-MFP processes. The experimental results are presented in Fig. 3. According to the experimental results, the optimum dosages were found as 50 $\mathrm{mg} / \mathrm{L}$ and $300 \mathrm{mg} / \mathrm{L}$ for CFP and MFP processes, respectively. The rise in iron concentration up to these optimized concentration led to a significant increase in color and COD removals, accroding to Eq. (1). However, the further increase in iron concentration results in a insufficient improvement in the oxidation efficiencies. While the color and COD removals were noted as $75.7 \%$ and $64.3 \%$ via $\mathrm{CFP}$ at $50 \mathrm{mg} / \mathrm{L} \mathrm{Fe}^{2+}$ concentration, the removal rates were found as $48.7 \%$ and $72.6 \%$ by MFP at $300 \mathrm{mg} / \mathrm{L}$ iron(II, III) oxide, respectively. By U-CFP and U-MFP processes, color and COD removals were determined as $94.8 \%$ and $81.2 \%$ at $50 \mathrm{mg} / \mathrm{L} \mathrm{Fe}^{2+}$ concentration as well as $35.65 \%$ and $70.4 \%$ at $200 \mathrm{mg} / \mathrm{L}$ iron(II, III) oxide, respectively.

As seen from Fig. 3, CFP and U-CFP processes were performed with higher efficiencies. The reason is that the catalyst iron which was utilized in CFP and U-CFP is dissolved and ready to react in accordance with Eq. (1). Oxidation efficiencies of MFP and U-MFP processes were found much lower in 1-h reaction period due to undissolved iron(II, III) oxide, so these processes required much more time for solid iron(II, III) oxide to be dissolved. On the other hand, as seen from Fig. 3, the removal efficiencies of U-CFP and U-MFP processes with ultrasonication were higher when compared with their individual modifications, that is, CFP and MFP. The reasons of these results were: (1) additional production of $\mathrm{OH}^{*}$ radicals by the effect of ultrasonication (Eq. (4)) $[14,15]$ and (2) ultrasonic regeneration of the catalyst iron which is re-usable in Fenton process (Eq. (5)) [16, 17], as it is indicated in Eq. (5).

As a result of dissolution of the catalyst iron(II, III) oxide powder in the acidic reaction solution, the mass of catalyst iron dosed to the reaction medium is reduced. The mass loss of catalyst iron(II, III) oxide powder was investigated experimentally in order to determine its reusability. These experiments were performed using the sythetic textile wastewater at $\mathrm{pH} 3$ for $1 \mathrm{~h}$ duration time without $\mathrm{H}_{2} \mathrm{O}_{2}$ addition. The experimental results showed that catalyst iron utilized in solid form was dissolved by about 14\% (as a mass ratio). Therefore, it was determined that iron(II, III) oxide powder (dosed to the reaction mixture) can be used 7 times as a catalyst
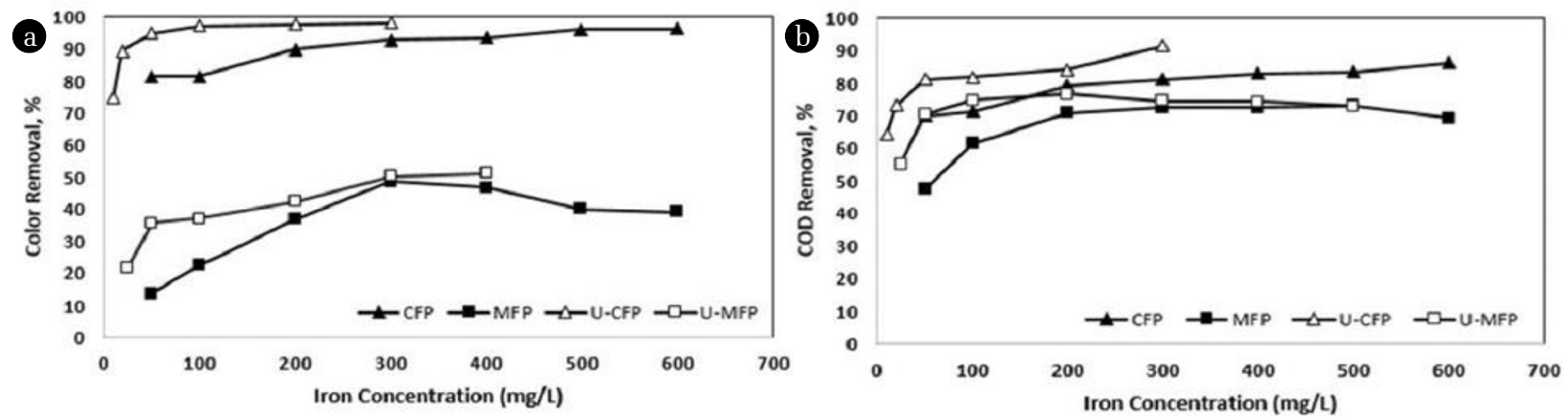

Fig. 3. Effects of iron concentration on $\mathrm{COD}$ and color removals from the synthetic textile wastewater. $\left[\right.$ Experimental conditions: $\mathrm{pH}=4$, $\left[\mathrm{H}_{2} \mathrm{O}_{2}\right]$ $=300 \mathrm{mg} / \mathrm{L}$ in CFP and U-CFP; $\mathrm{pH}=3,\left[\mathrm{H}_{2} \mathrm{O}_{2}\right]=300 \mathrm{mg} / \mathrm{L}$ in MFP and $\mathrm{pH}=4,\left[\mathrm{H}_{2} \mathrm{O}_{2}\right]=300 \mathrm{mg} / \mathrm{L}$ in U-MFP $]$. 
in MFP. For the same reason, chemical sludge produced in the MFP process was found to be much less. Thus, both reusability of the catalyst solid and the formation of much less chemical sludge makes the MFP process economically remarkable.

\subsection{Effect of Hydrogen Peroxide Concentration}

$\mathrm{H}_{2} \mathrm{O}_{2}$ is the main source of $\mathrm{OH}$ radicals produced in Fenton process. However, the excess amount of $\mathrm{H}_{2} \mathrm{O}_{2}$ in the reaction solution both increases the process cost and decreases the oxidation efficiency as a result of its radical scavenging effect [18]. Besides, the residual (unreacted) $\mathrm{H}_{2} \mathrm{O}_{2}$ in the treated wastewater causes a significant increase in effluent COD [18, 19]. For these reasons, the optimization of $\mathrm{H}_{2} \mathrm{O}_{2}$ concentration is very significant.

The influence of $\mathrm{H}_{2} \mathrm{O}_{2}$ concentration was investigated in the range of 25-600 mg/L in 4 different processes. The effects of $\mathrm{H}_{2} \mathrm{O}_{2}$ on the removals of color and COD are demonsrated in Fig. 4. As undertood from these graphes, the optimum concentrations were determined as $100 \mathrm{mg} / \mathrm{L}$ for CFP, as $200 \mathrm{mg} / \mathrm{L}$ for MFP, as $50 \mathrm{mg} / \mathrm{L}$ for U-CFP and as $50 \mathrm{mg} / \mathrm{L}$ for U-MFP. According to these optimum concentrations, the color and COD removals were decided as $72.5 \%$ and $69.7 \%$ for CFP; $87 \%$ and $75.8 \%$ for U-CFP; $40.6 \%$ and $64.8 \%$ for MFP and $49.9 \%$ and $73.1 \%$ for U-MFP, respectively. Therefore, additional improvements in color (14.5\%) and COD (6.1\%) removals were succeeded by decreasing $\mathrm{H}_{2} \mathrm{O}_{2}$ concentration in U-CFP, compared to CFP. When U-MFP was compared with individual MFP, color and COD removals were enhanced as $9.3 \%$ and $8.4 \%$, respectively. In the experiment performed with individual ultrasonication (without any chemical addition), 8\% color and 6\% COD removals were obtained. These results of individual ultrasonication experiment were due to only ultrasonic production of strong oxidizing radicals. Hereby, it was determined that the synergistic effects enhanced COD and color removals in U-CFP process [3, 14-17]. The reasons for this improvement are the regeneration of the dissolved catalyst iron in CFP, its re-usability in reaction medium and additional production of oxidizing agents. However, in U-MFP, the synergistic effects had a limited influence on COD and color removals due to the insufficient levels of dissolved ferrous ions in the reaction mixture. Because, solid iron(II, III) oxide (utilized as catalyst) must be dissolved in the medium for an effective oxidation in U-MFP.
As shown in Fig. 4, the rise in $\mathrm{H}_{2} \mathrm{O}_{2}$ concentration increased the reaction efficiency in accordance with Eq. (1). However, at the further concentrations, the excess amount of $\mathrm{H}_{2} \mathrm{O}_{2}$ in the reaction medium decreased the removal efficiencies due to the radical scavenging effect (Eq. (10)) [20, 21]. For U-CFP and U-MFP processes, higher efficiencies were obtained due to the production of hydroxyl radicals by ultrasonicaion. In a similar study, Ozdemir et al. [22] proved that the ultrasonicated Fenton process, which is the combination of conventional Fenton process and ultrasonication at $20 \mathrm{kHz}$, was more effective than individual Fenton process even at lower hydrogen peroxide dosages.

$$
\mathrm{H}_{2} \mathrm{O}_{2}+\mathrm{OH} \cdot \rightarrow \mathrm{HO}_{2} \cdot+\mathrm{H}_{2} \mathrm{O}
$$

\subsection{Kinetics Study}

By taking into consideration color and COD as the most important pollutant parameters in the textile wastewater, the kinetics study was carried out under optimized conditions for each process (summerized in Table 2) and the results are presented in Fig. 5.

Table 2. Optimum Conditions and Reaction Efficiencies for CFP, U-CFP, MFP and U-MFP Processes

\begin{tabular}{|c|c|c|c|c|c|}
\hline & \multirow{2}{*}{ pH } & \multirow{2}{*}{$\begin{array}{c}\text { [Catalyst Iron] } \\
\left(\mathrm{Fe}^{2+} / \mathrm{Fe}(\mathrm{II}, \mathrm{III}) \text { Oxide }\right), \\
\text { mg/L }\end{array}$} & \multirow{2}{*}{$\begin{array}{c}{\left[\mathrm{H}_{2} \mathrm{O}_{2}\right],} \\
\mathrm{mg} / \mathrm{L}\end{array}$} & \multicolumn{2}{|c|}{ Removal, \% } \\
\hline & & & & Color & COD \\
\hline CFP & 4 & 50 & 100 & 72.5 & 69.7 \\
\hline U-CFP & 4 & 50 & 50 & 87 & 75.8 \\
\hline MFP & 3 & 300 & 200 & 40.6 & 64.8 \\
\hline U-MFP & 4 & 50 & 300 & 49.9 & 73.1 \\
\hline
\end{tabular}

As shown in Fig. 5, the oxidation was occured very quickly in the first $2.5 \mathrm{~min}$, and it continued slowly in the following $57.5 \mathrm{~min}$ of the reaction period. Therefore, the oxidation period can be divided in two stages: (1) "rapid oxidation stage" in the first $2.5 \mathrm{~min}$, and (2) "slow oxidation stage" for the remaining part of the oxidation period. In the beginning of the reaction period, since Fenton reactants are more available that can not limit the reaction, the reaction occurred rapidly, according to Eq. (1). But
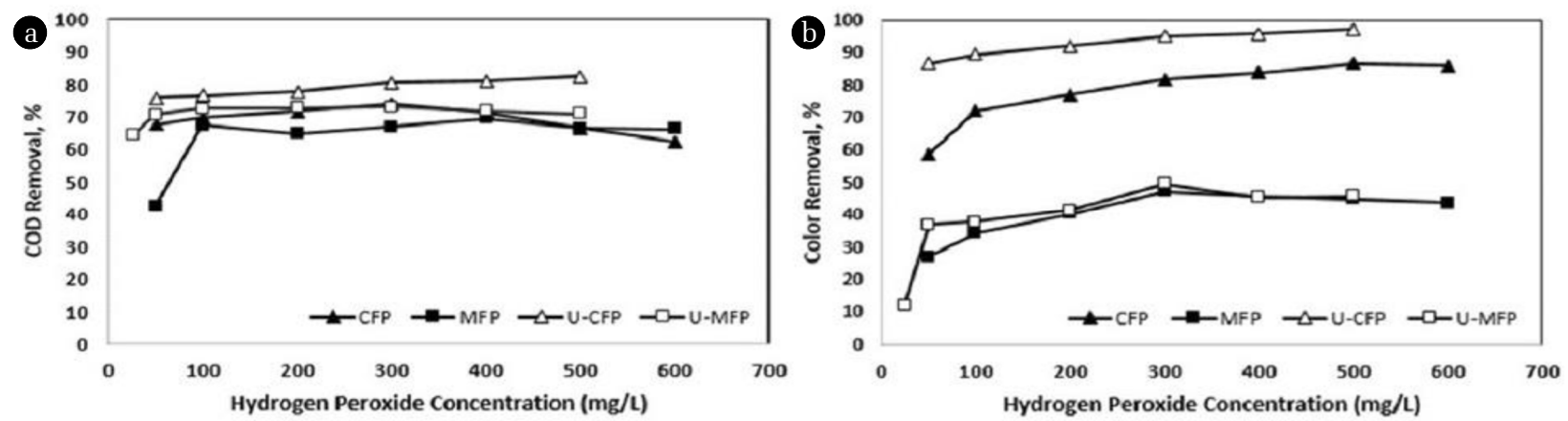

Fig. 4. Effects of hydrogen peroxide concentration on $\mathrm{COD}$ and color removals from the synthetic textile wastewater [Experimental conditions: $\mathrm{pH}=4,\left[\mathrm{Fe}^{2+}\right]=50 \mathrm{mg} / \mathrm{L}$ in CFP and U-CFP; $\mathrm{pH}=3$, [Fe(II, III) oxide] $=300 \mathrm{mg} / \mathrm{L}$ in MFP and pH $=4$, [Fe(II, III) oxide] $=50$ $\mathrm{mg} / \mathrm{L}$ in U-MFP]. 

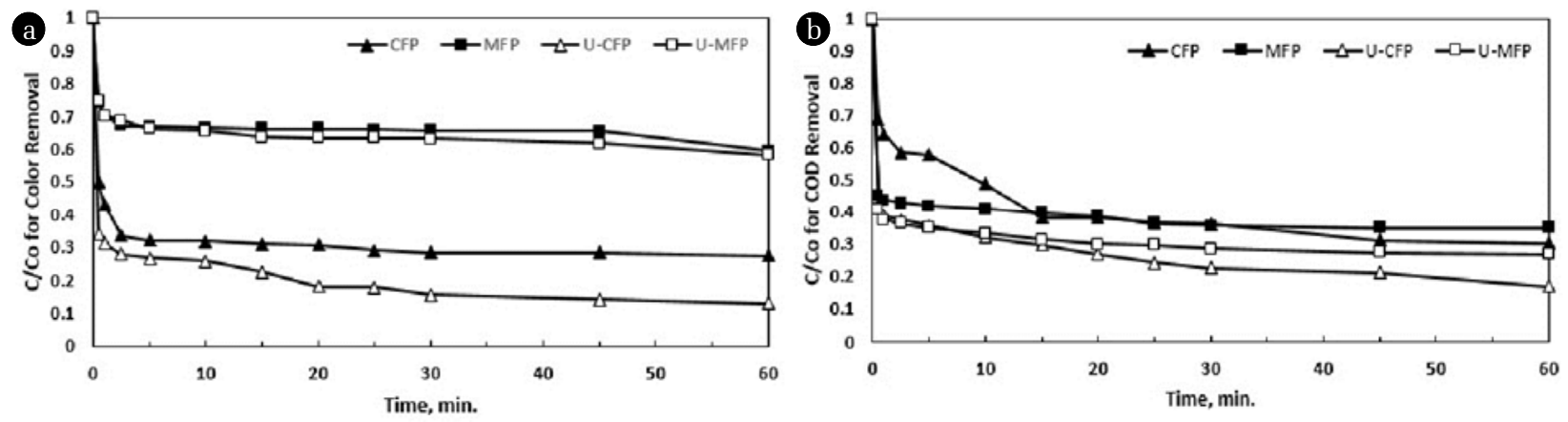

Fig. 5. COD and color removal curves of CFP, MFP, U-CFP and U-MFP.

the reaction rates were decelerated as the concentration of Fenton reagents in the reaction solution were decreased. Furthermore, it was determined that ultrasonicated Fenton processes were superior to CFP and MFP due to ultrasonic conversion of $\mathrm{Fe}^{3+}$ to $\mathrm{Fe}^{2+}$ and ultrasonic production of oxidizing agents like $\mathrm{H}_{2} \mathrm{O}_{2}, \mathrm{HO}_{2}$, $\mathrm{OH}^{*}$ and $\mathrm{O}^{*}$.

The experimental kinetics data given in Fig. 8 were tried to express with basic kinetics models. However, the kinetics data were not fitted to zero, first and second degree kinetics. Herewith, a mathematical model used in the study of Behnajady et al. [23] was applied to the kinetic data of this study. The equation of this mathematical model is presented in Eq. (11) and (12).

$$
\frac{C}{C_{O}}=1-\left(\frac{t}{m+b t}\right)
$$

where, $C_{0}$ is the initial concentration of the target pollutant; $C t$ is the concentration at time $\mathrm{t} ; b$ and $m$ are two dimensionless characteristic constants which are reaction kinetics of the model and maximum oxidation capacity of the process, respectively.

In order to apply the mathematical model, Eq. (11) is linearized and it is given as Eq. (12).

$$
\frac{t}{1-\left(\frac{C}{C_{O}}\right)}=m+b t
$$

According to Eq. (12), b, m and $\mathrm{R}^{2}$ (determination coefficient) values obtained from kinetics data are summarized in Table 3.

Table 3. Kinetic Constants and $R^{2}$ Values of the Mathematical Model

\begin{tabular}{lccccccc}
\hline \multirow{2}{*}{$\begin{array}{l}\text { Oxidation } \\
\text { process }\end{array}$} & \multicolumn{3}{c}{ Color removal } & & \multicolumn{3}{c}{ COD removal } \\
\cline { 2 - 4 } \cline { 6 - 8 } & $\mathbf{b}$ & $\mathbf{m}$ & $\mathbf{R}^{\mathbf{2}}$ & $\mathbf{b}$ & $\mathbf{m}$ & $\mathbf{R}^{\mathbf{2}}$ \\
\hline CFP & 0.7272 & 0.4657 & 0.9998 & 0.7123 & 2.3255 & 0.9965 \\
MFP & 0.3796 & 1.21 & 0.9871 & 0.6532 & 0.616 & 0.9995 \\
U-CFP & 0.8753 & 0.9763 & 0.9989 & 0.8231 & 1.4168 & 0.9971 \\
U-MFP & 0.4062 & 1.3304 & 0.9946 & 0.7335 & 0.6292 & 0.9996 \\
\hline
\end{tabular}

As it can be seen in Table $3, \mathrm{R}^{2}$ values obtained indicated that the experimental kinetics data were in good agreement with the applied mathematical model. Moreover, $\mathrm{b}$ and $\mathrm{m}$ values, calcu- lated according to the kinetics data, indicated that the most rapid and efficient process is U-CFP.

\section{Conclusions}

The following results were obtained in the present study in which Maxilon Red GRL 200\% was chosen as a model pollutant. In CFP and U-CFP, the oxidation reactions were happened very rapidly in the first $2.5 \mathrm{~min}$ and most of COD and color were removed in this rapid oxidation stage. In the remaining part of the period, the reaction rates were slown down depending on the decreases in the concentrations of Fenton reagents in the solution. However, it was determined that the color and COD removals in the slow oxidation stage is attributable to the potential of ultrasonication to produce oxidising agents such as $\mathrm{OH}^{*}, \mathrm{O}^{*}, \mathrm{HO}_{2}{ }^{\circ}$ and $\mathrm{H}_{2} \mathrm{O}_{2}$. The optimum conditions for U-CFP at $53 \mathrm{kHz}$ fixed frequency are $\mathrm{pH}$ $=4,\left[\mathrm{Fe}^{2+}\right]=50 \mathrm{mg} / \mathrm{L}$ and $\left[\mathrm{H}_{2} \mathrm{O}_{2}\right]=50 \mathrm{mg} / \mathrm{L}$; for individual CFP, the optimum conditions are $\mathrm{pH}=4,\left[\mathrm{Fe}^{2+}\right]=50 \mathrm{mg} / \mathrm{L},\left[\mathrm{H}_{2} \mathrm{O}_{2}\right]$ $=100 \mathrm{mg} / \mathrm{L}$; for U-MFP at $53 \mathrm{kHz}$ fixed frequency, $\mathrm{pH}=4$, [Fe(II, III) oxide $]=50 \mathrm{mg} / \mathrm{L},\left[\mathrm{H}_{2} \mathrm{O}_{2}\right]=300 \mathrm{mg} / \mathrm{L}$; for $\mathrm{MFP}, \mathrm{pH}=3$, $[\mathrm{Fe}(\mathrm{II}, \mathrm{III})$ oxide $]=300 \mathrm{mg} / \mathrm{L},\left[\mathrm{H}_{2} \mathrm{O}_{2}\right]=200 \mathrm{mg} / \mathrm{L}$. Under these optimized conditions, these processes are ordered according to color and COD removal efficiencies as U-CFP > CFP > U-MFP $>$ MFP. Hereby, by applying ultrasonication together with CFP, the pollutant removal efficiencies were improved by reducing the $\mathrm{H}_{2} \mathrm{O}_{2}$ dosage by half. Therefore, using fewer Fenton chemicals, higher treatment efficiencies were achieved. It is well known that usage of less hydrogen peroxide ensures more economical solution. The reasons of high oxidation yield were the production of additional oxidizing agents (such as $\mathrm{OH}^{*}, \mathrm{O}^{*}, \mathrm{~N}^{*}, \mathrm{H}^{*}$ and $\mathrm{H}_{2} \mathrm{O}_{2}$ ) and the regeneration of catalyst iron by ultrasonication. Quite lower efficiencies were provided in MFP and U-MFP due to the limited usage of the undissolved catalyst iron (nano sized iron(II, III) oxide). Because the catalyst nano-iron powder should be solved first before reacting. That is, the slow dissolution of the iron powder also limits the COD and color removal efficiencies. However, it was determined that the solid catalyst iron can be used 7 times in the MFP oxidation process. Besides, as a result of the ultrasonic regeneration of the iron in the reaction mixture, the catalyst iron dose was reduced from $300 \mathrm{mg} / \mathrm{L}$ to $50 \mathrm{mg} / \mathrm{L}$ without reducing the oxidation efficiency in U-MFP, compared to MFP. In addition, it was observed that the MFP and U-MPF processes produced 
much less the chemical treatment sludge, which is a complex and expensive problem as a hazardous waste. It was also seen that the experimental kinetics data were well suited to the mathematical model. According to the kinetic analyses and the applied model, U-CFP was the most rapid and efficient process due to the usage of the catalyst iron in dissolved form and sonochemical production of oxidizing agents.

\section{References}

1. Low FCF, Wu TY, Teh CY, Juan JC, Balasubramanian N. Investigation into photocatalytic decolorisation of CI Reactive Black 5 using titanium dioxide nanopowder. Color. Technol. 2012;128:44-50.

2. Subramonian W, Wu TY. Effect of enhancers and inhibitors on photocatalytic sunlight treatment of methylene blue. Water Air Soil Pollut. 2014;225:1-15.

3. Babuponnusami A, Muthukumar K. A review on Fenton and improvements to the Fenton process for wastewater treatment. J. Environ. Chem. Eng. 2014;2:557-572.

4. Gogate PR, Pandit AB. A review of imperative technologies for wastewater treatment I: Oxidation technologies at ambient conditions. Adv. Environ. Res. 2004;8:501-551.

5. Neyens E, Baeyens J. A review of classic Fenton's peroxidation as an advanced oxidation technique. J. Hazard. Mater. 2003;98:33-50.

6. Pilli S, Bhunia P, Yan S, LeBlanc RJ, Tyagi RD, Surampalli RY. Ultrasonic pretreatment of sludge: A review. Ultrason. Sonochem. 2011;18:1-18.

7. Teh CY, Wu TY, Juan JC. An application of ultrasound technology in synthesis of titania-based photocatalyst for degrading pollutant. Chem. Eng. J. 2017;317:586-612.

8. Sahinkaya S. COD and color removal from synthetic textile wastewater by ultrasound assisted electro-Fenton oxidation process. J. Ind. Eng. Chem. 2013;19:601-605.

9. Cetinkaya SG, Morcali MH, Akarsu S, Ziba CA, Dolaz M. Comparison of classic Fenton with ultrasound Fenton processes on industrial textile wastewater. Sustain. Environ. Res. 2018;28:165-170.

10. APHA/AWWA/WEF. In: Clesceri LS, Greenberg AE, Eaton AD, eds. Standard methods for the examination of water and wastewater. 20th ed. Washington D.C.: American Public Health Association, American Water Works Association, and Water
Environment Federation, Part 5220. 1998. p. 5-19.

11. Jeon BC, Nam SY, Kim YK. Treatment of pharmaceutical wastewaters by hydrogen peroxide and zerovalent iron. Environ. Eng. Res. 2014;19:9-14.

12. Wang N, Zheng T, Zhang G, Wang P. A review on Fenton-like processes for organic wastewater treatment. J. Environ. Chem. Eng. 2016;4:762-787.

13. Şahinkaya S. Decolorization of reactive orange 16 via ferrate(VI) oxidation assisted by sonication. Turk. J. Chem. 2017;41:577-586.

14. Singh J, Chang YY, Koduru JR, Yang JK, Singh DP. Rapid Fenton-like degradation of methyl orange by ultrasonically dispersed nano-metallic particles. Environ. Eng. Res. 2017;22:245-254

15. Hassani A, Karaca C, Karaca S, Khataee A, Açışlı Ö, Yılmaz B. Enhanced removal of basic violet 10 by heterogeneous sono-Fenton process using magnetite nanoparticles. Ultrason. Sonochem. 2018;42:390-402.

16. Adityosulindro S, Barthe L, González-Labrad K, Haza UJJ, Delmas H, Julcour C. Sonolysis and sono-Fenton oxidation for removal of ibuprofen in (waste) water. Ultrason. Sonochem. 2017;39:889-896.

17. Jih-Gaw L, Ying-Shih M. Oxidation of 2-chlorophenol in water by ultrasound/Fenton method. J. Environ. Eng. 2000;126:130-137.

18. Wang N, Zhen T, Zhang G, Wang P. A review on Fenton-like processes for organic wastewater treatment. J. Environ. Chem. Eng. 2016;4:762-787.

19. Lee E, Lee H, Kim YK, Sohn K, Lee K. Hydrogen peroxide interference in chemical oxygen demand during ozone based advanced oxidation of anaerobically digested livestock wastewater. Int. J. Environ. Sci. Technol. 2011;8:381-388.

20. Aygun A, Yllmaz T, Nas B, Berktay A. Effect of temperature on fenton oxidation of young landfill leachate: Kinetic assessment and sludge properties. Glob. Nest. J. 2012;14:487-495.

21. Subramonian W, Wu TY, Chai S-P. Photocatalytic degradation of industrial pulp and paper mill effluent using synthesized magnetic $\mathrm{Fe}_{2} \mathrm{O}_{3}-\mathrm{TiO}_{2}$ : Treatment efficiency and characterizations of reused photocatalyst. J. Environ. Manage. 2017;187:298-310.

22. Ozdemir C, Oden MK, Sahinkaya S, Guclu D. The sonochemical decolorisation of textile azo dye CI Reactive Orange 127. Color. Technol. 2011;127:268-273.

23. Behnajady MA, Modirshahla N, Ghanbary F. A kinetic model for the decolorization of C.I. acid yellow 23 by Fenton process. J. Hazard. Mater. 2007;148:98-102. 